\title{
SOCIAL SECURITY AND LONGEVITY
}

\author{
TORBEN M. ANDERSEN
}

CESIFO WORKING PAPER NO. 1577

CATEgORY 1: PubliC FinANCE

OCTOBER 2005
An electronic version of the paper may be downloaded
- from the SSRN website:
www.SSRN.com
- from the CESifo website: www.CESifo-group.de




\title{
SOCIAL SECURITY AND LONGEVITY
}

\begin{abstract}
Many countries face the problem of how to reform social security systems to cope with increasing life expectancy. This raises questions concerning both distribution and risk sharing across generations. These issues are addressed within an OLG model with stochastic life expectancy across generations and endogenous retirement decisions. The social optimum is shown to imply that retirement age should be proportional to longevity. Moreover, increasing longevity calls for pre-funding even if the utility of all generations is weighted equal to the objective discount rate. The social optimum cannot be decentralized due to a conflict between incentives and risk sharing. The implications of stylized social security systems for risk sharing and retirement incentives are analyzed.
\end{abstract}

JEL Code: H55, J11, J14, J18.

\author{
Torben M. Andersen \\ Department of Economics \\ University of Aarhus \\ Building 322 \\ 8000 Aarhus C \\ Denmark \\ tandersen@econ.au.dk
}




\section{Introduction}

Social security systems are in focus due to undergoing demographic shifts, in particular due to increasing longevity. According to UN forecasts (UN (2004)), life expectancy in western European countries is expected to rise on average 0.2 years per year over the next 50 years. Most countries face the challenge of how to exploit the opportunities arising from increasing longevity and the implied increase in the share of old people in populations. Obviously there is uncertainty about such figures, and therefore the issue is how both the trend and risk in longevity would affect social security systems.

Most countries have social security systems that do not include automatic responses to changes in longevity. In many countries there are fixed age limits for eligibility to pension (and early retirement), and these limits have remained invariant (or have even in some cases declined) despite increases in longevity (see e.g. IMF (2004)), cf. figure 1. Moreover most social security systems are of the defined benefit type providing a given benefit (could depend on past earning and be indexed) from the eligible age and until death, see e.g. Werding (2004), and thus unaffected by longevity. The need for reforms is on the agenda in many countries, and some countries have introduced explicit contingencies such that benefits adjust to expected life expectancy, ${ }^{1}$ or are discussing how eligibility ages can be indexed to life expectancy.

Figure 1: Life expectancy and age of retirement
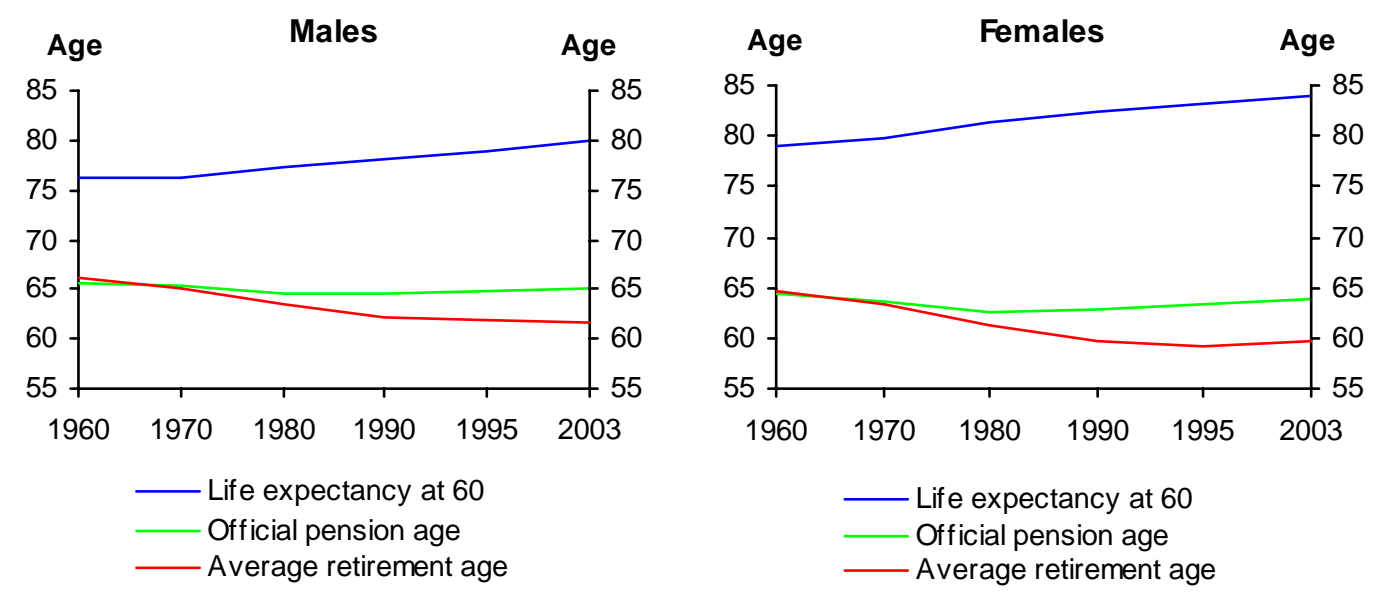

Note: Average for 20 OECD countries.

Source: Velfærdskommissionen (2005).

\footnotetext{
${ }^{1}$ In Sweden the current benefit flow is adjusted to life expectancy, and similar schemes are found in e.g. Italy, Poland and Latvia. In Germany benefits depend on the number of pensioners, and a number of countries have raised the eligibility age for pension. A recent reform proposal for Norway makes the eligibility age for pension contingent on expected life expectancy.
} 
The need for reforms to deal with increasing longevity is high on the agenda in many countries. An important question for policy reforms is how to deal with the implications for intergenerational distribution and risk sharing. This paper takes a step in this direction by raising the question of how social security systems should be designed to cope with trends and risk in longevity. In this context questions concerning consumption possibilities (pensions) and retirement are relevant, and therefore social security is considered in an overlapping generations model with varying longevity across different generations and endogenous retirement.

There is a relatively large literature addressing consequences of various forms of risk for public pension schemes, and it is well-known that the design of the system in general has important implications for how risk is diversified across time and generations. ${ }^{2}$ Bohn (2001) considers risk sharing in a PAYG system and finds that optimal risk sharing implies that all generations alive at a given point in time participate in the risk sharing. In recent papers Auerbach and Hassett (2002 a,b) have considered the issue of longevity for consumption risk sharing for the funding of pension systems, and argued that there is a case for precautionary savings or prefunding to deal with the risk associated with longevity across different generations. The present paper merges these two approaches by considering risk sharing both within periods and across time and thus generations. Moreover, it considers the retirement decision on par with consumption decisions.

The paper considers the optimal intergenerational distribution and risk sharing taking a utilitarian approach, but allows for a possible different weighting of the utility of different generations than implied by the subjective time preference of a given generation. ${ }^{3}$ This provides a useful benchmark case for evaluating the consequences of trends and risk in longevity. However, this approach turns out to have very strong implications for inter-generational distribution when there is a (upward) trend in longevity (the empirically relevant case). Under standard assumptions the optimal policy implies that current generations with low longevity should be pre-funding to support future generations with higher longevity. The reason being that generations with high longevity other things being equal will have a higher marginal utility of consumption as old. A striking implication is that future generations with higher longevity would be strictly better off than current generations with lower longevity. Obviously, this result depends on the utilitarian approach, and it can be questioned for a number of reasons. Therefore the paper also considers a scheme that entails risk sharing, but not redistribution across different generations.

This paper focuses on longevity, savings, retirement and social security. Therefore a number of simplifying assumptions are made to highlight the role of longevity. This includes that the marginal product of labour is constant (deterministic) and a small open economy assumption implying an exogenous interest

\footnotetext{
${ }^{2}$ It is also well-known that social security can offer risk sharing across generations (see e.g. Gordon and Varian (1988), Andersen and Dogonowski (2002), Ball and Romer (2001))

${ }^{3}$ For a discussion of problems in assessing intergenerational fairness and equity see e.g. Padilla (2002) and Woodward (2000).
} 
(making it possible to disregard feedbacks to rates of return and the capital stock).

This paper is organized as follows: Section 2 sets up the overlapping generations model with different and stochastic life expectancy of different generations and endogenous retirement. The optimal allocation across generations for the social planner is considered in section 3, while the decentralized market allocation is considered in section 4 . The possibility of implementing the social optimum via an appropriate design of a social security scheme is considered in section 5 , while section 6 offers a few conclusions.

\section{Overlapping generations model - variable life time and endogenous retirement}

Consider an economy with access to an international capital market offering a risk-free asset with return $r$, which for simplicity is assumed constant throughout time.

Agents live through two life phases, one denoted young and the other old. The first phase has a given length normalized to unity, while the second has a random length $\beta(\leq 1)$. Denote the generation being young in period $t$ as generation $t$. In youth they work and enjoy consumption $c_{1 t}$, yielding utility ${ }^{4}$

$$
u\left(c_{1 t}\right) u^{\prime}>0, u^{\prime \prime} \geq 0
$$

Disutility of work during youth is constant and therefore disregarded to simplify the exposition.

In the second period of life, agents of generation $t$ may be alive for a period of length $\beta_{t+1}$ (the total length of the period being normalized to one, $\beta_{t+1} \leq 1$ ), and they work a fraction of this period $\alpha_{t+1}\left(\leq \beta_{t+1}\right)$. The retirement period is thus $\beta_{t+1}-\alpha_{t+1}$. The marginal product of labour $y$ is constant and the same for young and old workers, and the labour market is assumed competitive.

Total consumption as old is $c_{2 t+1}$ yielding a consumption stream of $\frac{c_{2 t+1}}{\beta_{t}}$, and total utility from consumption in the old phase of life is (see Auerbach and Hassett (2002a,b))

$$
\beta_{t} u\left(\frac{c_{2 t+1}}{\beta_{t}}\right)
$$

Note that this specification implies that agents value long life time, but the utility function implies a trade-off between longevity and consumption. ${ }^{5}$ Life length $\beta_{t+1}$ is uncertain as young in period $t$, but known with certainty at the start of period $t+1$. This specification makes it possible to focus on risk sharing associated with uncertain life expectancy across generations in a simple way. ${ }^{6}$

\footnotetext{
${ }^{4}$ Note that the utility function is assumed to be the same across generations.

${ }^{5}$ It could be argued that preferences are lexiographic, i.e. longevity is evaluated above material consumption flows.

${ }^{6}$ It would be straightforward to allow longevity to be unkown for each single individual by introducing an annuities market in which agents can insure themselves against idiosyn-
} 
Disutility of work as old is given as

$$
\alpha_{t} v\left(\frac{\alpha_{t}}{\beta_{t}}\right) ; v^{\prime}>0, v^{\prime \prime}>0, \lim _{\alpha \longrightarrow \beta} v^{\prime}=\infty
$$

Hence, the usual convexity of disutility of work is assumed, and the last condition ensures that there always is some "retirement" period $(\alpha<\beta)$. For later reference it is useful to define the marginal disutility of work as old by

$$
\frac{\partial}{\partial \alpha}\left(\alpha_{t} v\left(\frac{\alpha_{t}}{\beta_{t}}\right)\right) \equiv \eta\left(\frac{\alpha}{\beta}\right)=v\left(\frac{\alpha}{\beta}\right)+\frac{\alpha}{\beta} v^{\prime}\left(\frac{\alpha}{\beta}\right)
$$

where $\eta^{\prime}=2 v^{\prime}+\frac{\alpha}{\beta} v^{\prime \prime}>0, n^{\prime \prime}=3 v^{\prime \prime}+\frac{\alpha}{\beta} v^{\prime \prime \prime} \gtreqless 0$. Note that for $\frac{\alpha}{\beta}$ sufficiently large it follows that (given that $\lim _{\alpha \longrightarrow \beta} v^{\prime}=\infty$ ) $v^{\prime \prime \prime}>0$.

Lifetime utility can thus be written

$$
V_{t}\left(c_{1 t}, c_{2 t+1}, \alpha_{t+1}, \beta_{t+1}\right)=u\left(c_{1 t}\right)+\frac{1}{1+\rho} E_{t}\left[\beta_{t+1} u\left(\frac{c_{2 t+1}}{\beta_{t+1}}\right)-\alpha_{t+1} v\left(\frac{\alpha_{t+1}}{\beta_{t+1}}\right)\right]
$$

where $\rho$ is the subjective discount rate. Note that $V_{c_{1}}^{\prime}>0, V_{c_{2}}^{\prime}>0, V_{\alpha}^{\prime}<0$, and $V_{\beta}^{\prime} \lesseqgtr 0$.

The aggregate resource constraint reads

$$
b_{t+1}=(1+r)\left[b_{t}+y+\alpha_{t} y-c_{1 t}-c_{2 t}\right]
$$

where $b$ denotes national wealth, and $r$ is the (exogenous) return in the international capital market. Note that the marginal product of labour is assumed constant (no real capital).

\section{The social planner allocation}

The objective of the social planner respecting individual preference orderings, but assigning a discount rate $\theta$ to the welfare of future generations can be written ${ }^{7}$

$$
\Psi_{t}=(1+\theta) E_{t}\left[u\left(\bar{c}_{1 t-1}\right)+S\left(\mathbf{x}_{t}\right)+\frac{1}{1+\theta} S\left(\mathbf{x}_{t+1}\right)+\left(\frac{1}{1+\theta}\right)^{2} S\left(\mathbf{x}_{t+2}\right)++\right]
$$

where the vector $\mathbf{x}_{t}$ is defined as $\mathbf{x}_{t} \equiv\left(c_{1 t}, c_{2 t}, \alpha_{t}, \beta_{t}\right)$, and the $S$-function gives the utility generated to young and old alive in a given period, i.e.

$$
S\left(\mathbf{x}_{t}\right)=S\left(c_{1 t}, c_{2 t}, \alpha_{t}, \beta_{t}\right) \equiv \frac{1}{1+\theta} u\left(c_{1 t}\right)+\frac{1}{1+\rho}\left[\beta_{t} u\left(\frac{c_{2 t}}{\beta_{t}}\right)-\alpha_{t} v\left(\frac{\alpha_{t}}{\beta_{t}}\right)\right]
$$

cratic risks. Given the focus on intergenerational distribution and risk sharing, this aspect is neglected. See e.g. Yaari (1965) and Diamond (2004).

${ }^{7}$ This is not an unproblematic assumption. See Padilla (2002) for a discussion of some of the problems arising when analyzing intergenerational questions assuming that future generations hold the same utility function, and that utilities can be discounted. 
with the properties $S_{c_{1}}^{\prime}>0, S_{c_{2}}^{\prime}>0, S_{\alpha}^{\prime}<0$, and $S_{\beta}^{\prime} \lesseqgtr 0$.

The first-order conditions to the social planner problem of maximizing (2) subject to (1) yield

$$
\begin{gathered}
\frac{1}{1+\theta} u^{\prime}\left(c_{1 t}\right)=\frac{1}{1+\rho} u^{\prime}\left(\frac{c_{2 t}}{\beta_{t}}\right) \text { (within period consumption allocation) } \\
u^{\prime}\left(\frac{c_{2 t}}{\beta_{t}}\right)=\frac{1+r}{1+\theta} \frac{1+\rho}{1+\theta} E u^{\prime}\left(\frac{c_{2 t+1}}{\beta_{t+1}}\right) \text { (across period consumption allocation) } \\
u^{\prime}\left(\frac{c_{2 t}}{\beta_{t}}\right) y=\eta\left(\frac{\alpha_{t}}{\beta_{t}}\right) \text { (retirement age) } \\
\eta\left(\frac{\alpha_{t}}{\beta_{t}}\right)=\frac{1+r}{1+\theta} \frac{1+\rho}{1+\theta} E_{t} \eta\left(\frac{\alpha_{t+1}}{\beta_{t+1}}\right) \text { (across period retirement allocation) }
\end{gathered}
$$

Condition (3) determines allocation of consumption and thus consumption risk sharing between generations alive in a given period. It says that the optimal allocation equalizes the weighted marginal utilities of consumption for young and old. This is the condition found in Bohn (2001) showing that all generations alive in a given period should participate equally in risk sharing. Condition (4) determines consumption allocation across generations living at different points in time, i.e. the marginal utility of consumption for current old relative to the expected marginal utility of consumption for the next generation of old. This condition determines risk sharing across periods and thus generations alive at different points in time, and is also found in Auerbach and Hassett (2002a,b). Retirement is determined by condition (5) giving the standard condition linking the marginal rate of substitution between consumption and leisure to the marginal product of labour. Finally, condition (6) gives the determination of retirement across different generations, and therefore also the inter-generational risk sharing involved in retirement and thus work decisions.

To see the implications of these conditions more clearly, it is useful to consider the issues of intergenerational distribution and risk sharing separately.

\section{The deterministic case}

Assume that life time is known for all current and future generations, i.e. there is no risk concerning longevity for any generation. In this no-risk case, the first order conditions determine intergenerational distribution of consumption and retirement opportunities, and conditions (3) to (6) can be summarized in the following two conditions

$$
\begin{aligned}
u^{\prime}\left(\frac{c_{2 t}}{\beta_{t}}\right) & =\frac{1+r}{1+\theta} \frac{1+\rho}{1+\theta} u^{\prime}\left(\frac{c_{2 t+1}}{\beta_{t+1}}\right) \\
\eta\left(\frac{\alpha_{t}}{\beta_{t}}\right) & =\frac{1+r}{1+\theta} \frac{1+\rho}{1+\theta} \eta\left(\frac{\alpha_{t+1}}{\beta_{t+1}}\right)
\end{aligned}
$$


i.e. the marginal utility of consumption for the current old should be proportional to the marginal utility of consumption for tomorrow's old, and similarly the marginal disutility of work (and thus the fraction of the second period spent on the labour market) for the current old should be proportional to the disutility of work for the next generation of old.

Equation (7) and (8) also bring forth that the factor $\frac{1+r}{1+\theta} \frac{1+\rho}{1+\theta}$ plays a key role in determining the profile for consumption and retirement across generations. This factor depends on the objective discount rate $(r)$ relative to the individual subjective discount rate $(\rho)$, and the latter relative to the political discount rate between generations $(\theta)$. The less weight policy makers attach to the utility of future generations (the higher $\theta$ ) the smaller the discount factor $\frac{1+r}{1+\theta} \frac{1+\rho}{1+\theta}$. If $\frac{1+r}{1+\theta} \frac{1+\rho}{1+\theta}<1$ the profile of consumption tends to be falling and the retirement age relative to longevity increasing, i.e. there is redistribution favouring current generations at the cost of future generations, and vice versa for $\frac{1+r}{1+\theta} \frac{1+\rho}{1+\theta}>1$.

Since this effect is straightforward and driven by assumptions on the weight to different generations in the social welfare function, the following proceeds under the assumption that $r=\rho=\theta$, i.e. $\frac{1+r}{1+\theta} \frac{1+\rho}{1+\theta}=1$, which eliminates effects arising from different weighting of the utility of different generations. This will in the following be referred to as "neutral weighting", and in this case we have

$$
\begin{aligned}
c_{1 t} & =\frac{c_{2 t}}{\beta_{t}}=\frac{c_{2 t+1}}{\beta_{t+1}}=c_{1 t+1} \\
\frac{\alpha_{t}}{\beta_{t}} & =\frac{\alpha_{t+1}}{\beta_{t+1}}
\end{aligned}
$$

Consumption is the same across age groups and time, and the fraction of old age spent on the labour market is constant across all generations and thus time, i.e. all generations have a retirement age $(\alpha)$ proportional to longevity $(\beta)$. Note that the retirement period becomes

$$
\beta_{t+1}-\alpha_{t+1}=\beta_{t+1}\left(1-\frac{\alpha_{t+1}}{\beta_{t+1}}\right)
$$

and thus proportional to longevity. In short, higher longevity is split between later retirement and a longer retirement period. Note also that it is an implication that consumption falls. ${ }^{8}$

Note that the social optimum even under neutral weighting implies redistribution from generations with low longevity to generations with high longevity. To see this, note that even though all generations work the same proportion of life time as old, this does not automatically leave the same consumption flow since the consumption possibilities would have to be spread over a longer time period. Consumption as old and/or young will therefore be lower, but the social optimum also has consumption invariant to longevity. Hence, there must be some redistribution across generations with different longevity. This reflects

\footnotetext{
${ }^{8}$ This is so since the extra production due to later retirement does not fully cover the extra consumption due to longer longevity, cf. below.
} 
that persons with longer lives other things being equal would have a higher marginal utility of consumption: therefore the social planner wants to redistribute from generations with low longevity (low marginal utility of consumption) to persons with high longevity (high marginal utility of consumption). Clearly, in social optimum the marginal utility of consumption is constant across time and generations.

A final and relevant implication given current demographic forecasts is that the social optimal plan implies pre-funding if longevity is increasing, i.e. generations with longer lives will in net terms be receiving more than generations with shorter lives. To see this, assume that $\beta_{t+1}>\beta_{t}$. In this case the optimal plan implies that consumption resources spent on generation $t+1$ exceed those spent on generation $t$, i.e. (9) implies

$$
c_{2 t+1}-c_{2 t}=c_{2 t+1}\left(1-\frac{\beta_{t}}{\beta_{t+1}}\right)>0
$$

However, since $\frac{\alpha}{\beta}$ is the same across all generations, it also follows that generation $t+1$ will be working more than generation $t$, and the extra output produced is

$$
y\left[\alpha_{t+1}-\alpha_{t}\right]=y\left(\frac{\alpha}{\beta}\right)^{*}\left[\beta_{t+1}-\beta_{t}\right]>0
$$

Hence, in net terms the extra resources going to generation $t+1$ seen relative to generation $t$ are $^{9}$

$c_{2 t+1}\left(1-\frac{\beta_{t}}{\beta_{t+1}}\right)-y\left(\frac{\alpha}{\beta}\right)^{*}\left[\beta_{t+1}-\beta_{t}\right]=\left[\beta_{t+1}-\beta_{t}\right]\left[\frac{c_{2 t+1}}{\beta_{t+1}}-y\left(\frac{\alpha}{\beta}\right)^{*}\right]>0$ for $\beta_{t+1}>\beta_{t}$

If $\beta$ is increasing over time, the social optimal allocation implies that current young generations have to be net contributors to the future generations with longer lives. Note also that it is an implication that future generations would be better off since

$$
\beta_{t+1}\left[u\left(\frac{c_{2 t+1}}{\beta_{t+1}}\right)-\frac{\alpha_{t+1}}{\beta_{t+1}} v\left(\frac{\alpha_{t+1}}{\beta_{t+1}}\right)\right]>\beta_{t}\left[u\left(\frac{c_{2 t}}{\beta_{t}}\right)-\frac{\alpha_{t}}{\beta_{t}} v\left(\frac{\alpha_{t}}{\beta_{t}}\right)\right]
$$

and consumption as young is the same. The utility gain as old is proportional to the increase in longevity $\left(\frac{\beta_{t+1}}{\beta_{t}}\right)$.

Note that this result is driven by the fact that longer life, ceteris paribus, means less consumption as old. This causes marginal utility of consumption to be higher for generations who live longer. For this reason they will also tend to retire relatively later (see below) and accordingly have higher disutility of work. Both mechanisms make the social planner redistribute consumption possibilities (and thus induce earlier retirement) in favour of generations with high

\footnotetext{
${ }^{9}$ Observe that $\frac{c_{2 t+1}}{\beta_{t+1}}-y\left(\frac{\alpha}{\beta}\right)^{*}>0$. This follows from observing that the social optimal allocation implies that $c_{1}=\frac{c_{2}}{\beta}$; hence $c_{1}+c_{2}=(1+\beta) c_{1}$ resources produced are $y+\alpha y=$ $(1+\alpha) y$, and since $\alpha<\beta$, it follows that $c_{1}<y$. Therefore $c_{2}>\alpha y$.
} 
longevity. Note that this result is derived under neutral weighting. Moreover, these effects do not depend on the particular specification of the utility function, and therefore this result is conjectured to generalize.

\section{Risk sharing}

Turning next to the implications of the social optimum for risk sharing across generations, it follows from (4) and (6) that

$$
\begin{aligned}
\frac{c_{2 t}}{\beta_{t}} \lesseqgtr E_{t}\left[\frac{c_{2 t+1}}{\beta_{t+1}}\right] \text { for } u^{\prime \prime \prime} \gtreqless 0 \\
\frac{\alpha_{t}}{\beta_{t}} \lesseqgtr E_{t}\left[\frac{\alpha_{t+1}}{\beta_{t+1}}\right] \text { for } \eta^{\prime \prime} \gtreqless 0
\end{aligned}
$$

The condition in (11) is well-known from the literature on consumption under uncertainty. If the third derivative of the utility function is positive, the consumption profile is expected to increase, ${ }^{10}$ i.e. expected consumption of future old is larger than consumption of present old. In this case there is precautionary savings, i.e. some pre-funding has to be established to allow an (expected) increasing consumption profile. Vice versa for the third derivative being negative. Similar conditions hold for retirement. If $\eta^{\prime \prime}$ is positive, future generations are expected to spend a larger fraction of their life time working, and vice versa.

Observe that if $u^{\prime \prime \prime}>0$ and $\eta^{\prime \prime}>0$, the profile for both consumption and retirement will be increasing ${ }^{11}$ i.e. future generations can expect to have higher consumption, but also to work a relatively larger share of the old age period (relatively later retirement), and mutatis mutandis for other combinations of the signs of the two terms.

Note that the savings or prefunding arising as a response to risk are different from the pre-funding associated with redistribution across generations with different longevity (cf. above). The former is like a buffer to compensate for the fact that longevity is risky, and therefore there is scope for risk sharing across generations, while the latter arises from motive to redistribute across generations.

\section{Decentralized outcome - no social security sys- tem}

We now turn to the outcome arising in a decentralized market economy in which there is no social security system. The individual decision problem is solved in the usual backward way by first considering the decision of the old given their savings decision as young, and subsequently the decision problem as young is

\footnotetext{
${ }^{10}$ This is well-known from the literature on consumption under risk, cf. Lippman and McCall (1981) for a survey. See e.g. Cabarello (1991) and Talmain (1998) for analytical solutions to problems of consumption allocation under risk. The main source of risk in these papers is income risk, whereas the present paper focuses on uncertain life-time. However, the qualitative implications are the same.

${ }^{11}$ Note that due to the seperability assumption the two conditions are not directly related.
} 
worked out. The problem for an old person in period $t+1$ is to decide on retirement (labour supply as old), i.e.

$$
\operatorname{Max}_{\alpha_{t+1}} \beta_{t+1} u\left(\frac{\alpha_{t+1} y+p_{t+1}}{\beta_{t+1}}\right)-\alpha_{t+1} v\left(\frac{\alpha_{t+1}}{\beta_{t+1}}\right)
$$

where $p_{t+1} \equiv(1+r)\left(y-c_{1 t}\right)$ is the period $t+1$ value to the old of the period $t$ savings they made as young, and this is in the following denoted the pension capital.

The retirement decision yields the following first order condition

$$
u^{\prime}\left(\frac{c_{2 t+1}}{\beta_{t+1}}\right) y=\eta\left(\frac{\alpha_{t+1}}{\beta_{t+1}}\right)
$$

showing that at the margin the individual decision making leads to the same retirement decision as that by the social planner (compare to (5)). Condition (13) defines the implicit function

$$
\frac{\alpha_{t+1}}{\beta_{t+1}}=\phi\left(\frac{c_{2 t+1}}{\beta_{t+1}}\right)
$$

where $\phi^{\prime}=\frac{u^{\prime \prime}}{\eta^{\prime}}<0$. Using (14), it follows ${ }^{12}$ that $^{13}$

$$
\frac{c_{2 t+1}}{\beta_{t+1}}=\psi\left(\frac{p_{t+1}}{\beta_{t+1}}\right)
$$

It is straightforward to verify that $\psi^{\prime}>0$. Utility for period $t+1$ old can now be written

$$
\varphi\left(\frac{p_{t+1}}{\beta_{t+1}}\right)=\beta_{t+1}\left[u\left(\psi\left(\frac{p_{t+1}}{\beta_{t+1}}\right)\right)-\phi\left(\psi\left(\frac{p_{t+1}}{\beta_{t+1}}\right)\right) v\left(\phi\left(\psi\left(\frac{p_{t+1}}{\beta_{t+1}}\right)\right)\right)\right]
$$

where $\varphi^{\prime}>0, \varphi^{\prime \prime} \gtreqless 0$.

The period $t$ consumption decision maximizes

$$
u\left(c_{1 t}\right)+\frac{1}{1+\rho} E_{t}\left[\varphi\left(\frac{p_{t+1}}{\beta_{t+1}}\right)\right]
$$

subject to the constraint

$$
c_{1 t}+\frac{1}{1+r} p_{t+1}=y
$$

which yields the following first order condition ${ }^{14}$

$$
u^{\prime}\left(c_{1 t}\right)=-\frac{1}{1+\rho} E_{t}\left[\beta_{t+1} \varphi^{\prime}\left(\frac{p_{t+1}}{\beta_{t+1}}\right)\right]
$$

\footnotetext{
${ }^{12}$ Consumption as old can from the budget constraint be written as $\frac{c_{2 t+1}}{\beta_{t+1}}=\frac{\alpha_{t+1}}{\beta_{t+1}} y+\frac{p_{t+1}}{\beta_{t+1}}$.

${ }^{13}$ The function $\psi$ is the inverse of $\frac{c_{2 t+1}}{\beta_{t+1}}-\phi\left(\frac{c_{2 t+1}}{\beta_{t+1}}\right) y$.

${ }^{14}$ Note that the implicit function theorem implies that $\varphi^{\prime}\left(\frac{p_{t+1}}{\beta_{t+1}}\right)=-\frac{1}{\beta_{t+1}} u^{\prime}\left(\frac{c_{2 t+1}}{\beta_{t+1}}\right)(1+r)$.
} 
Hence (15) can be written (note $r=\rho$ )

$$
u^{\prime}\left(c_{1 t}\right)=E_{t}\left[u^{\prime}\left(\frac{c_{2 t+1}}{\beta_{t+1}}\right)\right]
$$

which also shows that the consumption decision coincides with the intertemporal allocation of consumption chosen by the social planner, compare to (4). Hence neither labour supply nor saving are distorted at the margin, but there is an inefficiency since the opportunities for allocating across time and generations are not fully exploited. This applies both to consumption and retirement, that is, neither condition (3) nor (6) holds. To see this, consider the condition for allocating consumption across periods/generations requiring that $c_{1 t}=\frac{c_{2 t}}{\beta_{t}}$. From the individual decision making follows $\frac{c_{2 t+1}}{\beta_{t+1}}=\psi\left(\frac{p_{t+1}}{\beta_{t+1}}\right)$, and imposing the risk sharing condition implies

$$
c_{1 t+1}=\psi\left(\frac{p_{t+1}}{\beta_{t+1}}\right)
$$

which is only possible if consumption by the current young depends on the longevity of the current old and their consumption as young. This is clearly not ensured by the decentralized equilibrium. With (3) violated, it follows directly that (6) does not hold.

\section{Retirement bias}

To see the direction in which individual decision making is biased relative to the social optimum assume that $\beta$ is deterministic. We shall establish that generations with high longevity (high $\beta$ ) work more than implied by the social optimum, and vice versa for generations with a low $\beta$. The social optimum implies that $\frac{\alpha}{\beta}$ should be the same across two generations with different longevity $(\beta)$. However, the decentralized outcome implies that $\frac{\alpha}{\beta}$ is increasing (and $c_{1}$ and $\frac{c_{2}}{\beta}$ decreasing) in $\beta$. To see this, denote the decentralized allocation $\left\{c_{10}, c_{20}, \alpha_{0}\right\}$ for a generation with $\beta=\beta_{0}$. Individual decision making fulfills

$$
\begin{aligned}
\frac{\alpha_{t+1}}{\beta_{t+1}} & =\phi\left(\frac{c_{2 t+1}}{\beta_{t+1}}\right) \phi^{\prime}<0 \\
\frac{c_{2 t+1}}{\beta_{t+1}} & =\frac{\alpha_{t+1}}{\beta_{t+1}}+\frac{p_{t+1}}{\beta_{t+1}}
\end{aligned}
$$

Note first that $\frac{\alpha}{\beta}$ and $\frac{c_{2}}{\beta}$ are inversely related via (18). Consider first the possibility that $c_{1}$ and $\frac{c_{2}}{\beta}$ are increasing (and hence $\frac{\alpha}{\beta}$ decreasing) in $\beta$. It is easily seen that an increase in both $c_{1}$ and $\frac{c_{2}}{\beta}$ and a decrease in $\frac{\alpha}{\beta}$ violate the budget constraint. Hence this is not feasible. Next is it possible to have $c_{1}$ decreasing, but $\frac{c_{2}}{\beta}$ increasing (and hence $\frac{\alpha}{\beta}$ decreasing) in $\beta$ ? Considering the condition determining intertemporal consumption allocation, we have

$$
u^{\prime}\left(c_{1 t}\right)=u^{\prime}\left(\frac{c_{2}}{\beta}\right)
$$


Clearly a decrease in $c_{1}$ and an increase in $\frac{c_{2}}{\beta}$ violate this condition. Hence, the claim has been proven. This shows that the decentralized outcome leads to a bias in the retirement decision with generations with low longevity retiring too early, and generations with high longevity too late.

\section{Savings bias}

Since less risk is diversified in the decentralized outcome than in the social optimum, it also follows that the savings decision is affected. If risk induces precautionary savings $\left(u^{\prime \prime \prime}>0\right)$, then the larger risk would imply more savings in the decentralized outcome, i.e. consumption as young would be lower. The flipside is that old age consumption possibilities are larger on average, which also via an income effect tends to lower the retirement age. Ex post the obvious effect is that generations with high longevity would work more than generations with low longevity.

\section{Implementing the social optimum}

Can the social optimum be reached as a decentralized outcome under some social security scheme? To see that a fundamental question of risk vs incentives is involved, take outset in the finding above that the decentralized solution leaves insufficient risk sharing. The condition for optimal risk sharing (11) would require a transfer (positive or negative) to old $x_{t+1}$ such that

$$
\frac{c_{2 t+1}}{\beta_{t+1}}=\frac{\alpha_{t+1} y+(1+r)\left(y-c_{1 t}\right)+x_{t}}{\beta_{t+1}}=c_{1 t+1}
$$

which requires a transfer

$$
x_{t}=\beta_{t+1} c_{1 t+1}-\alpha_{t+1} y-(1+r)\left(y-c_{1 t}\right)
$$

This transfer ensuring efficient risk sharing is increasing (and proportional) to longevity and decreasing in labour income and pension capital. Obviously this transfer would distort both the retirement and the savings decision by eliminating the private incentive to work as old and to save as young. The first best is thus not reachable as a decentralized competitive equilibrium, and the question is how various more pragmatic pension schemes are situated on the trade-off between risk sharing and incentives. Before turning to this issue, it is interesting to consider a special case where the first best can be achieved.

\section{Special case - lump sum taxation and ex ante identical generations}

There is, however, one special case in which it is possible to reach the social optimum, and which actually implies that all risks can be fully diversified. Consider the case where all generations ex ante are alike, that is they have the same expected longevity (and all other moments), i.e. the conditional life expectancies are equal to unconditional longevity for all generations. Specifically it is assumed that $\beta_{t}$ is $i i d$ with mean $\bar{\beta}$ and variance $\sigma^{2}$,

$$
E_{t} \beta_{t+1}=E_{t+1} \beta_{t+2}=E \beta \text { for all } t
$$


Under assumption (20) all agents make the same consumption and thus savings decision as young, i.e. $c_{1 t}=c_{1 t+1}$ for all $t$. Period $t+1$ consumption is

$$
\frac{c_{2 t+1}}{\beta_{t+1}}=\frac{\alpha_{t+1}}{\beta_{t+1}} y+\frac{(1+r)\left(y-c_{1 t}\right)}{\beta_{t+1}}+s_{t+1}
$$

where $s$ is a flow transfer to old during remaining life time. Consider transfer schemes of the following family

$$
s_{t+1}=\kappa_{0}-\frac{\kappa_{1}}{\beta_{t+1}}
$$

where $\kappa_{0}$ and $\kappa_{1}$ are parameters (exogenous) from the individual point of view. This transfer rule implies

$$
\frac{c_{2 t+1}}{\beta_{t+1}}=\frac{\alpha_{t+1}}{\beta_{t+1}} y+\frac{(1+r)\left(y-c_{1 t}\right)}{\beta_{t+1}}+\kappa_{0}-\frac{\kappa_{1}}{\beta_{t+1}}
$$

If $\kappa_{1}$ is set equal to

$$
\kappa_{1}=(1+r)\left(y-c_{1 t}\right)
$$

it follows that

$$
\frac{c_{2 t+1}}{\beta_{t+1}}=\frac{\alpha_{t+1}}{\beta_{t+1}} y+\kappa_{0}
$$

Therefore

$$
\frac{\alpha_{t+1}}{\beta_{t+1}}=\phi\left(\kappa_{0}\right)
$$

i.e. $\frac{\alpha_{t+1}}{\beta_{t+1}}=\frac{\alpha_{t}}{\beta_{t}}=\frac{\alpha}{\beta}$ for all $t$.

This shows that there is a transfer scheme of the form (21), which ensures that all have the same consumption as young, and the same relative retirement age $\left(\frac{\alpha}{\beta}\right)$, therefore consumption as old is also the same, i.e.

$$
\frac{c_{2 t+1}}{\beta_{t+1}}=\frac{\alpha}{\beta} y+\kappa_{0}
$$

The expected transfer to a given generation is

$$
E \beta_{t+1} s_{t+1}=\kappa_{0} E \beta-\kappa_{1}
$$

To reach first best we require

$$
c_{1}=\frac{c_{2}}{\beta}
$$

which is ensured if

$$
\kappa_{0}=c_{1}-\frac{\alpha}{\beta} y
$$

and $\kappa_{1}$ is determined by (22). 
It follows that this scheme is feasible since the expected transfer to any generation is zero, i.e. ${ }^{15}$

$$
E\left(\beta_{t+1} s_{t+1}\right)=\left(c_{1}-\frac{\alpha}{\beta} y\right) E \beta+(1+r)\left(y-c_{1}\right)=0
$$

Note that the transfer scheme in this special case has the same form as (19) and implies that lump sum taxation is feasible.

\section{Intergenerational risk sharing without redistribution}

Given that the utilitarian solution tends to benefit generations with higher longevity (even under equal weighting), the premises on which the social welfare function is based can be questioned. This raises deep questions concerning sustainability and intergenerational equity, which it is beyond this paper to deal with in great detail. Instead it is asked whether it is possible to establish intergenerational risk sharing without redistribution via the pension scheme.

To address this issue, consider the following linear class of transfers to generation $t$ as old

$$
s_{t+1}=a\left(\beta_{t+1}-E_{t} \beta_{t+1}\right)
$$

i.e. the transfer is dependent on the actual life time relative to expected life time for the generation, and therefore by construction the ex ante expected transfer to a given generation is zero, i.e. $E_{t} s_{t+1}=0$. Such a scheme therefore implies potential risk sharing, but no redistribution across generations.

Under this scheme we have

$$
\frac{p_{t+1}}{\beta_{t+1}}=\frac{(1+r)\left(y-c_{1 t}\right)}{\beta_{t+1}}+a-a \frac{E_{t} \beta_{t+1}}{\beta_{t+1}}
$$

It is an immediate implication that old age consumption becomes less sensitive to longevity for $a>0$. This scheme also affects retirement decisions since

$$
\frac{\alpha_{t+1}}{\beta_{t+1}}=\phi\left(\psi\left(\frac{(1+r)\left(y-c_{1 t}\right)}{\beta_{t+1}}+a-a \frac{E \beta_{t}}{\beta_{t+1}}\right)\right)
$$

The effect is driven by an income effect since the pension scheme does not affect the marginal return to work. This risk sharing scheme affects labour supply in the sense that if $\widetilde{\alpha}$ denotes retirement age in the absence of risk sharing $(a=0)$ then

$$
\begin{aligned}
& \alpha_{t+1}>\widetilde{\alpha}_{t+1} \text { if } \beta_{t+1}<E \beta_{t+1} \\
& \alpha_{t+1}=\widetilde{\alpha}_{t+1} \text { if } \beta_{t+1}=E \beta_{t+1} \\
& \alpha_{t+1}<\widetilde{\alpha}_{t+1} \text { if } \beta_{t+1}>E \beta_{t+1}
\end{aligned}
$$

\footnotetext{
${ }^{15}$ Since we have from the individual budget constraint (for $c_{1}=\frac{c_{2}}{\beta}$ ) $y+\frac{1}{1+r} \frac{\alpha}{\beta} \beta_{t+1} y=$ $c_{1}+\frac{c_{2}}{1+r}=c_{1}\left[1+\frac{\beta_{t+1}}{1+r}\right]$. The argument relies on the fact that with a perfect international capital market, the risk can be fully diversified since the transfer has an expected value and variance of zero, cf. Appendix A.
} 
i.e. those with longevity above the mean will retire later, and vice versa. In this way retirement also becomes more smoothened in the sense that the relative retirement age $\left(\frac{\alpha}{\beta}\right)$ is less sensitive to longevity $(\beta)$.

The next question is the choice of the parameter $a$ maximizing expected utility, and this is found as the solution to the problem of maximizing the following expression wrt $a$

$$
u\left(c_{1 t}\right)+\frac{1}{1+\rho} E_{t}\left[\varphi\left(\frac{p_{t+1}}{\beta_{t+1}}\right)\right]=u\left(c_{1 t}\right)+\frac{1}{1+\rho} E_{t}\left[\varphi\left(\frac{(1+r)\left(y-c_{1 t}\right)}{\beta_{t+1}}+a-a \frac{E \beta_{t}}{\beta_{t+1}}\right)\right]
$$

subject to the constraint

$$
u^{\prime}\left(c_{1 t}\right)=-\frac{1}{1+\rho} E_{t}\left[\varphi^{\prime}\left(\frac{(1+r)\left(y-c_{1 t}\right)}{\beta_{t+1}}+a-a \frac{E \beta_{t}}{\beta_{t+1}}\right)\right]
$$

Which, cf. appendix $B$, yields the first order condition

$$
E_{t}\left[\varphi^{\prime}\left(\frac{p_{t+1}}{\beta_{t+1}}\right)\left[\frac{E \beta_{t}}{\beta_{t+1}}-1\right]\right]=0
$$

It is shown in Appendix $B$ that $a>0$ showing that there is an optimal risk sharing scheme, which diversifies risk from changes in longevity (transfers depend on $\beta-E \beta)$. Note that this can be achieved by making retirement ages and pensions depend on longevity.

\section{Social security systems - benefits and retirement}

Given that no social security scheme can achieve the social optimum, it is of interest to consider the implications of various simple or pragmatic schemes.

Let $S$ denote the capitalized value of the pension entitlement. It follows that the old age consumption flow becomes

$$
\frac{c_{2}}{\beta}=\frac{\alpha}{\beta} y+\frac{(1+r)\left(y-c_{1}\right)}{\beta}+\frac{S}{\beta}
$$

and the retirement decision is determined by

$$
\eta\left(\frac{\alpha}{\beta}\right)=u^{\prime}\left(\frac{\alpha}{\beta} y+\frac{(1+r)\left(y-c_{1}\right)}{\beta}+\frac{S}{\beta}\right)
$$

Table 1: Pension schemes: consumption flows and work incentives

\begin{tabular}{|l|l|l|l|}
\hline Type & $\begin{array}{l}\text { Accumulated pension } \\
S\end{array}$ & $\begin{array}{l}\text { Consumption flow as old: } \\
S / \beta\end{array}$ & $\begin{array}{l}\text { Return to work: } \\
\partial\left(\frac{c_{2}}{\beta}\right) / \partial\left(\frac{\alpha}{\beta}\right)\end{array}$ \\
\hline lump sum & $s$ & $\frac{s}{\beta}$ & $y$ \\
\hline proportional & $s \beta$ & $s$ & $y$ \\
\hline actual retirement & $s(\beta-\alpha)$ & $s-\frac{\alpha}{\beta}$ & $y-s$ \\
\hline stipulated retirement & $s(\beta-\bar{\alpha})$ & $s-\frac{\bar{\alpha}}{\beta}$ & $y$ \\
\hline actual retirement & $s(\beta-\bar{\alpha})$ for $\alpha \leq \bar{\alpha}$ & $s-\frac{\bar{\alpha}}{\beta}$ for $\alpha \leq \bar{\alpha}$ & $y$ for $\alpha \leq \bar{\alpha}$ \\
with minimum age & $s(\beta-\alpha)$ for $\alpha>\bar{\alpha}$ & $s-\frac{\alpha}{\beta}$ for $\alpha>\bar{\alpha}$ & $y-s$ for $\alpha>\bar{\alpha}$ \\
\hline
\end{tabular}


Table 1 outlines some stylized schemes and their implications for the consumption flow and retirement incentives for old people. Two issues are of interest: their implications for risk sharing and the incentives they leave concerning retirement. The following schemes are considered: (i) a lump sum scheme offering a given sum to all old irrespective of longevity and retirement age, (ii) a proportional scheme offering a pension proportional to life time, (iii) a scheme offering a pension from the time of retirement and the remaining life time, (iv) a scheme with a stipulated retirement age offering a pension proportional to life time, but from a given fixed retirement age irrespective of actual retirement age, and (v) a scheme offering a pension depending on the actual retirement age, but at a stipulated earliest age $(\bar{\alpha})$.

Risk sharing is reflected in the extent to which the consumption flow as old depends on longevity $(\beta)$. As seen from table 1 , a lump sum pension to all implies a negative relation between longevity and consumption flow, for a proportional scheme consumption is unaffected, and for the remaining schemes the consumption flow is increasing in longevity. Risk sharing in consumption thus gives an argument for pensions being proportional to life time.

The retirement decision depends both on the incentive to work and the income effect arising from the pension transfer. The marginal return to work (postponing) retirement is unaffected except for scheme (iii) and (v) where the pension depends on the actual retirement age. Incentives underlying retirement thus provide an argument for having the (present value) pension entitlements independent of actual retirement age. This is equivalent to having an actuarial fair scheme in which the pension flow depends on the retirement age, but the present value of pension entitlements is independent.

Evaluated from the implications for risk sharing and incentives there are thus arguments for having pensions proportional to longevity, but unrelated to retirement age.

Finally, note that imposing a mandatory retirement age would prevent the retirement bias - generations with high longevity retire too late. However, a binding retirement age would ceteris paribus worsen the situation for those with high life expectancy. They want - ceteris paribus - to work longer to avoid too low consumption as old. Hence, this only works if accompanied by transfers!

\section{Concluding remarks}

Increasing longevity raises important questions on how to design social security systems. The present paper has focussed on the fact that this involves questions of both intergenerational distribution and risk sharing. Two important elements that are difficult to disentangle in practice. This is underlined by the fact that even with neutral weighting in the objective function of the social planner, the optimal allocation implies that generations with higher longevity are better off than generations with shorter longevity. This of course points to the underlying welfare gains from the current upward trend in longevity, but it also points to a difficult policy choice - is it reasonable that current generations 
with shorter longevity should be prefunding to support future generations with higher longevity?

However, even under the constraint that there should be no (expected) redistribution across generations, there is scope for risk diversification. The risk is an unexpected long life length and therefore the need for income support for a longer period of time. It is possible to build such risk diversification into social security schemes by making pensions entitlements proportional to longevity (by paying a certain period-by-period sum for the remaining life time). However, to avoid distorting incentives, pension entitlements (in present value terms) should be unaffected by actual retirement age. In fact the social optimum (with neutral weighting) calls for retirement age - and thus the retirement period - to be proportional to (expected) life length.

\section{References}

Andersen, T.M. and R.R. Dogonowski, 2002, Social Insurance and the Public Budget, Economica, 69, 415-432.

Auerbach, A. and K. Hassett, 2002a, Fiscal policy and uncertainty, International Finance, 5(2), 229-242.

Auerbach, A. and K. Hassett, 2002b, Optimal long-run fiscal policy: Constraints, Preferences and the Resolution of Uncertainty, NBER Working Papper 7036 .

Ball, L: and N.G. Romer, 2001, Intergenerational Risk Sharing in the Spirit of Arrow, Debreu, and Rawls, with Applications to Social Security Design, NBER Working Paper 8270.

Bohn, H., 2001, Social Security and Demographic Uncertainty: The Risk Sharing Properties of Alternative Policies, in Risk Aspects of Investment Based Social Security Reform, ed. by J.Campbell and M. Feldstein, University of Chicago Press, Chicago.

Caballero, R., 1991, Earnings Uncertainty and Aggregate Wealth Accumulation, American Economic Review, 81(4), 859-871

Diamond., P., 2004, Social security, American Economic Review, 94, 1-24.

Gordon, R. and H. Varian, 1988, Intergenerational Risk Sharing, Journal of Public Economics, 37, 185-202.

IMF, 2004, World Economic Outlook, September 2004

Lippmann,S. and J. McCall, 1981, The Economics of Uncertainty: Selected Topics and Probabilistic Methods, in Handbook of Mathematical Economics, ed. by K.J.Arrow and M.D. Intrilligator, ch. 6, North-Holland, Amsterdam.

Padilla, E., 2002, Intergenerational equity and sustainability, Ecological Economics, 41, 69-83.

Talmain, G., 1998, An analytical approximate solution to the problem of precautionary savings, Journal of Economic Dynamics and Control, 23, 113124.

United Nations, 2004, World Population in 2300, UN, New York.

Velfærdskommissionen, 2005, Fremtidens velfærd - sådan gør andre lande, analyserapport. 
Werding, M., 2004, Assessing Old-age Pension Benefits: The Rules Applied in Different Countries, CESifo Bulletin, 2(2), 55-63.

Woodward, R.T., 2000, Sustainability as Intergenerational Fairness: Efficiency, Uncertainty, and Numerical Methods, American Journal of Agricultural Economics, 82, 581-593.

Yaari, M., 1965, Uncertain Lifetime, Insurance and the Theory of the Consumer, Review of Economic Studies, 32, 137-50.

\section{Appendix A}

Consider the following present value of a stochastic variable $x_{t}$, which is iid with mean zero and variance $\sigma^{2}$,

$V_{t, N}=\frac{1}{N}\left[x_{t}+\frac{1}{1+r} x_{t+1}+\left(\frac{1}{1+r}\right)^{2} x_{t+2}++++++\left(\frac{1}{1+r}\right)^{N-1} x_{t++N-1}\right]$

Hence

$$
E\left(V_{t, N}\right)=0
$$

and

$$
\begin{aligned}
\operatorname{Var}\left(V_{t, N}\right) & =\frac{1}{N^{2}}\left[1+\frac{1}{1+r}+\left(\frac{1}{1+r}\right)^{2}++++++\left(\frac{1}{1+r}\right)^{N-1}\right] \sigma^{2} \\
& =\frac{1}{N^{2}}\left[\frac{\left(\frac{1}{1+r}\right)^{N}-1}{\frac{1}{1+r}-1}\right] \sigma^{2}
\end{aligned}
$$

where

$$
\operatorname{Var}\left(V_{t, N}\right) \rightarrow 0 \text { for } N \rightarrow 0
$$

\section{Appendix B}

Mandatory retirement age - does not solve the problem since it is not one-sided

Does this give support to a mandatory retirement age? - but this violates freedom of choice

$$
\widetilde{\alpha}_{t+1}=\beta_{t+1} c
$$

Hence

$$
\frac{\alpha}{\beta}=\frac{\widetilde{\alpha}_{t+1}}{\beta_{t+1}}=c
$$

provided $u^{\prime}>\eta$ (evaluated at the proper points). epsilon incentive compatibility requirement 


$$
\begin{aligned}
\frac{c_{2 t+1}}{\beta_{t+1}} & =\frac{\widetilde{\alpha}_{t+1}}{\beta_{t+1}}+\frac{(1+r)\left(y-c_{1 t}\right)}{\beta_{t+1}}+s_{t+1} \\
& =c+\frac{(1+r)\left(y-c_{1 t}\right)}{\beta_{t+1}}+s_{t+1}
\end{aligned}
$$

Consumption sharing implies

$$
\begin{aligned}
c+\frac{(1+r)\left(y-c_{1 t}\right)}{\beta_{t+1}}+s_{t+1} & =c+\frac{(1+r)\left(y-c_{1 t-1}\right)}{\beta_{t}}+s_{t} \\
s_{t+1}-s_{t} & =\frac{(1+r)\left(y-c_{1 t-1}\right)}{\beta_{t}}-\frac{(1+r)\left(y-c_{1 t}\right)}{\beta_{t+1}}
\end{aligned}
$$

if consumption is approximately the same

$$
s_{t+1}-s_{t}=(1+r)\left(y-c_{1 t-1}\right)\left[\frac{1}{\beta_{t}}-\frac{1}{\beta_{t+1}}\right]
$$

is the simple approximate expression for this?

Take out all the trend - given mean and only fluctuations around this mean

\section{Appendix C}

The first order condition to the maximization problem is

$$
u^{\prime}\left(c_{1 t}\right) \frac{\partial c_{1 t}}{\partial a}+\frac{1}{1+\rho} E_{t}\left[\varphi^{\prime}\left(\frac{p_{t+1}}{\beta_{t+1}}\right)\left[-\frac{(1+r)}{\beta_{t+1}} \frac{\partial c_{1 t}}{\partial a}+1-\frac{E \beta_{t}}{\beta_{t+1}}\right]\right]=0
$$

or

$\left[u^{\prime}\left(c_{1 t}\right)-\frac{1}{1+\rho} E_{t}\left[\varphi^{\prime}\left(\frac{p_{t+1}}{\beta_{t+1}}\right) \frac{(1+r)}{\beta_{t+1}}\right]\right] \frac{\partial c_{1 t}}{\partial a}=\frac{1}{1+\rho} E_{t}\left[\varphi^{\prime}\left(\frac{p_{t+1}}{\beta_{t+1}}\right)\left[\frac{E \beta_{t}}{\beta_{t+1}}-1\right]\right]$

which by the use of the first order condtion () can be written

$$
E_{t}\left[\varphi^{\prime}\left(\frac{p_{t+1}}{\beta_{t+1}}\right)\left[\frac{E \beta_{t}}{\beta_{t+1}}-1\right]\right]=0
$$

Define

$$
\Gamma\left(\beta_{t+1}\right)=E_{t}\left[\varphi^{\prime}\left(\frac{p_{t+1}}{\beta_{t+1}}\right)\left[\frac{E \beta_{t}}{\beta_{t+1}}-1\right]\right]
$$

Hence

$\Gamma^{\prime}\left(\beta_{t+1}\right)=E_{t}\left[\varphi^{\prime \prime}\left(\frac{p_{t+1}}{\beta_{t+1}}\right)\left(-\frac{(1+r)\left(y-c_{1 t}\right)}{\left(\beta_{t+1}\right)^{2}}\right)\left[\frac{E \beta_{t}}{\beta_{t+1}}-1\right]-\varphi^{\prime}\left(\frac{p_{t+1}}{\beta_{t+1}}\right) \frac{E \beta_{t}}{\left(\beta_{t+1}\right)^{2}}\right]$ 
Observe that

$$
\Gamma^{\prime}\left(\beta_{t+1}\right)<0 \text { for } \beta_{t+1}=E \beta_{t+1}
$$

and

$\Gamma^{\prime \prime}\left(\beta_{t+1}\right)=E_{t}\left[\begin{array}{c}\varphi^{\prime \prime \prime}\left(\frac{p_{t+1}}{\beta_{t+1}}\right)\left(-\frac{(1+r)\left(y-c_{1 t}\right)}{\left(\beta_{t+1}\right)^{2}}\right)^{2}\left[\frac{E \beta_{t}}{\beta_{t+1}}-1\right]+\varphi^{\prime \prime}\left(\frac{p_{t+1}}{\beta_{t+1}}\right)\left(2 \frac{(1+r)\left(y-c_{1 t}\right)}{\left(\beta_{t+1}\right)^{3}}\right)\left[\frac{E \beta_{t}}{\beta_{t+1}}-1\right] \\ -\varphi^{\prime \prime}\left(\frac{p_{t+1}}{\beta_{t+1}}\right)\left(-\frac{(1+r)\left(y-c_{1 t}\right)}{\left(\beta_{t+1}\right)^{2}}\right)\left[\frac{E \beta_{t}}{\left(\beta_{t+1}\right)^{2}}\right]-\varphi^{\prime \prime}\left(\frac{p_{t+1}}{\beta_{t+1}}\right)\left(-\frac{(1+r)\left(y-c_{1 t}\right)}{\left(\beta_{t+1}\right)^{2}}\right) \frac{E \beta_{t}}{\left(\beta_{t+1}\right)^{2}} \\ +\varphi^{\prime}\left(\frac{p_{t+1}}{\beta_{t+1}}\right) 2 \frac{E \beta_{t}}{\left(\beta_{t+1}\right)^{3}}\end{array}\right]$

and therefore

$\begin{aligned} & \Gamma^{\prime \prime}\left(\beta_{t+1}\right)=-\varphi^{\prime \prime}\left(\frac{p_{t+1}}{\beta_{t+1}}\right)\left(-\frac{(1+r)\left(y-c_{1 t}\right)}{\left(\beta_{t+1}\right)^{2}}\right)\left[\frac{E \beta_{t}}{\left(\beta_{t+1}\right)^{2}}\right]-\varphi^{\prime \prime}\left(\frac{p_{t+1}}{\beta_{t+1}}\right)\left(-\frac{(1+r)\left(y-c_{1 t}\right)}{\left(\beta_{t+1}\right)^{2}}\right) \frac{E \beta_{t}}{\left(\beta_{t+1}\right)^{2}} \\ &+\varphi^{\prime}\left(\frac{p_{t+1}}{\beta_{t+1}}\right) 2 \frac{E \beta_{t}}{\left(\beta_{t+1}\right)^{3}}\end{aligned}$

for $\beta_{t+1}=E \beta_{t+1}$. If $\Gamma^{\prime \prime}<0$ we have

$$
\Gamma\left(\beta_{t+1}\right)=E_{t}\left[\varphi^{\prime}\left(\frac{p_{t+1}}{\beta_{t+1}}\right)\left[\frac{E \beta_{t}}{\beta_{t+1}}-1\right]\right]<0 \text { for } a=0
$$

Note also that

$$
\begin{gathered}
\frac{\partial E_{t}\left[\varphi^{\prime}\left(\frac{p_{t+1}}{\beta_{t+1}}\right)\left[\frac{E \beta_{t}}{\beta_{t+1}}-1\right]\right]}{\partial a}=E_{t}\left[-\varphi^{\prime}\left(\frac{p_{t+1}}{\beta_{t+1}}\right)\left[\frac{E \beta_{t}}{\beta_{t+1}}-1\right]^{2}\right]>0 \text { for } a=0 \\
\left.\frac{\partial E_{t}\left[\varphi^{\prime}\left(\frac{p_{t+1}}{\beta_{t+1}}\right)\left[\frac{E \beta_{t}}{\beta_{t+1}}-1\right]\right]}{\partial a}\right|_{a=0}>0
\end{gathered}
$$

Hence, it is optimal to choose $a>0$. 


\section{CESifo Working Paper Series}

(for full list see www.cesifo-group.de)

1517 Kira Boerner and Silke Uebelmesser, Migration and the Welfare State: The Economic Power of the Non-Voter?, August 2005

1518 Gabriela Schütz, Heinrich W. Ursprung and Ludger Wößmann, Education Policy and Equality of Opportunity, August 2005

1519 David S. Evans and Michael A. Salinger, Curing Sinus Headaches and Tying Law: An Empirical Analysis of Bundling Decongestants and Pain Relievers, August 2005

1520 Michel Beine, Paul De Grauwe and Marianna Grimaldi, The Impact of FX Central Bank Intervention in a Noise Trading Framework, August 2005

1521 Volker Meier and Matthias Wrede, Pension, Fertility, and Education, August 2005

1522 Saku Aura and Thomas Davidoff, Optimal Commodity Taxation when Land and Structures must be Taxed at the Same Rate, August 2005

1523 Andreas Haufler and Søren Bo Nielsen, Merger Policy to Promote 'Global Players'? A Simple Model, August 2005

1524 Frederick van der Ploeg, The Making of Cultural Policy: A European Perspective, August 2005

1525 Alexander Kemnitz, Can Immigrant Employment Alleviate the Demographic Burden? The Role of Union Centralization, August 2005

1526 Baoline Chen and Peter A. Zadrozny, Estimated U.S. Manufacturing Production Capital and Technology Based on an Estimated Dynamic Economic Model, August 2005

1527 Marcel Gérard, Multijurisdictional Firms and Governments' Strategies under Alternative Tax Designs, August 2005

1528 Joerg Breitscheidel and Hans Gersbach, Self-Financing Environmental Mechanisms, August 2005

1529 Giorgio Fazio, Ronald MacDonald and Jacques Mélitz, Trade Costs, Trade Balances and Current Accounts: An Application of Gravity to Multilateral Trade, August 2005

1530 Thomas Christiaans, Thomas Eichner and Ruediger Pethig, A Micro-Level 'Consumer Approach’ to Species Population Dynamics, August 2005

1531 Samuel Hanson, M. Hashem Pesaran and Til Schuermann, Firm Heterogeneity and Credit Risk Diversification, August 2005 
1532 Mark Mink and Jakob de Haan, Has the Stability and Growth Pact Impeded Political Budget Cycles in the European Union?, September 2005

1533 Roberta Colavecchio, Declan Curran and Michael Funke, Drifting Together or Falling Apart? The Empirics of Regional Economic Growth in Post-Unification Germany, September 2005

1534 Kai A. Konrad and Stergios Skaperdas, Succession Rules and Leadership Rents, September 2005

1535 Robert Dur and Amihai Glazer, The Desire for Impact, September 2005

1536 Wolfgang Buchholz and Wolfgang Peters, Justifying the Lindahl Solution as an Outcome of Fair Cooperation, September 2005

1537 Pieter A. Gautier, Coen N. Teulings and Aico van Vuuren, On-the-Job Search and Sorting, September 2005

1538 Leif Danziger, Output Effects of Inflation with Fixed Price- and Quantity-Adjustment Costs, September 2005

1539 Gerhard Glomm, Juergen Jung, Changmin Lee and Chung Tran, Public Pensions and Capital Accumulation: The Case of Brazil, September 2005

1540 Yvonne Adema, Lex Meijdam and Harrie A. A. Verbon, The International Spillover Effects of Pension Reform, September 2005

1541 Richard Disney, Household Saving Rates and the Design of Social Security Programmes: Evidence from a Country Panel, September 2005

1542 David Dorn and Alfonso Sousa-Poza, Early Retirement: Free Choice or Forced Decision?, September 2005

1543 Clara Graziano and Annalisa Luporini, Ownership Concentration, Monitoring and Optimal Board Structure, September 2005

1544 Panu Poutvaara, Social Security Incentives, Human Capital Investment and Mobility of Labor, September 2005

1545 Kjell Erik Lommerud, Frode Meland and Odd Rune Straume, Can Deunionization Lead to International Outsourcing?, September 2005

1546 Robert Inklaar, Richard Jong-A-Pin and Jakob de Haan, Trade and Business Cycle Synchronization in OECD Countries: A Re-examination, September 2005

1547 Randall K. Filer and Marjorie Honig, Endogenous Pensions and Retirement Behavior, September 2005

1548 M. Hashem Pesaran, Til Schuermann and Bjoern-Jakob Treutler, Global Business Cycles and Credit Risk, September 2005 
1549 Ruediger Pethig, Nonlinear Production, Abatement, Pollution and Materials Balance Reconsidered, September 2005

1550 Antonis Adam and Thomas Moutos, Turkish Delight for Some, Cold Turkey for Others?: The Effects of the EU-Turkey Customs Union, September 2005

1551 Peter Birch Sørensen, Dual Income Taxation: Why and how?, September 2005

1552 Kurt R. Brekke, Robert Nuscheler and Odd Rune Straume, Gatekeeping in Health Care, September 2005

1553 Maarten Bosker, Steven Brakman, Harry Garretsen and Marc Schramm, Looking for Multiple Equilibria when Geography Matters: German City Growth and the WWII Shock, September 2005

1554 Paul W. J. de Bijl, Structural Separation and Access in Telecommunications Markets, September 2005

1555 Ueli Grob and Stefan C. Wolter, Demographic Change and Public Education Spending: A Conflict between Young and Old?, October 2005

1556 Alberto Alesina and Guido Tabellini, Why is Fiscal Policy often Procyclical?, October 2005

1557 Piotr Wdowinski, Financial Markets and Economic Growth in Poland: Simulations with an Econometric Model, October 2005

1558 Peter Egger, Mario Larch, Michael Pfaffermayr and Janette Walde, Small Sample Properties of Maximum Likelihood Versus Generalized Method of Moments Based Tests for Spatially Autocorrelated Errors, October 2005

1559 Marie-Laure Breuillé and Robert J. Gary-Bobo, Sharing Budgetary Austerity under Free Mobility and Asymmetric Information: An Optimal Regulation Approach to Fiscal Federalism, October 2005

1560 Robert Dur and Amihai Glazer, Subsidizing Enjoyable Education, October 2005

1561 Carlo Altavilla and Paul De Grauwe, Non-Linearities in the Relation between the Exchange Rate and its Fundamentals, October 2005

1562 Josef Falkinger and Volker Grossmann, Distribution of Natural Resources, Entrepreneurship, and Economic Development: Growth Dynamics with Two Elites, October 2005

$1563 \mathrm{Yu}-\mathrm{Fu}$ Chen and Michael Funke, Product Market Competition, Investment and Employment-Abundant versus Job-Poor Growth: A Real Options Perspective, October 2005

1564 Kai A. Konrad and Dan Kovenock, Equilibrium and Efficiency in the Tug-of-War, October 2005 
1565 Joerg Breitung and M. Hashem Pesaran, Unit Roots and Cointegration in Panels, October 2005

1566 Steven Brakman, Harry Garretsen and Marc Schramm, Putting New Economic Geography to the Test: Free-ness of Trade and Agglomeration in the EU Regions, October 2005

1567 Robert Haveman, Karen Holden, Barbara Wolfe and Andrei Romanov, Assessing the Maintenance of Savings Sufficiency Over the First Decade of Retirement, October 2005

1568 Hans Fehr and Christian Habermann, Risk Sharing and Efficiency Implications of Progressive Pension Arrangements, October 2005

1569 Jovan Žamac, Pension Design when Fertility Fluctuates: The Role of Capital Mobility and Education Financing, October 2005

1570 Piotr Wdowinski and Aneta Zglinska-Pietrzak, The Warsaw Stock Exchange Index WIG: Modelling and Forecasting, October 2005

1571 J. Ignacio Conde-Ruiz, Vincenzo Galasso and Paola Profeta, Early Retirement and Social Security: A Long Term Perspective, October 2005

1572 Johannes Binswanger, Risk Management of Pension Systems from the Perspective of Loss Aversion, October 2005

1573 Geir B. Asheim, Wolfgang Buchholz, John M. Hartwick, Tapan Mitra and Cees Withagen, Constant Savings Rates and Quasi-Arithmetic Population Growth under Exhaustible Resource Constraints, October 2005

1574 Christian Hagist, Norbert Klusen, Andreas Plate and Bernd Raffelhueschen, Social Health Insurance - the Major Driver of Unsustainable Fiscal Policy?, October 2005

1575 Roland Hodler and Kurt Schmidheiny, How Fiscal Decentralization Flattens Progressive Taxes, October 2005

1576 George W. Evans, Seppo Honkapohja and Noah Williams, Generalized Stochastic Gradient Learning, October 2005

1577 Torben M. Andersen, Social Security and Longevity, October 2005 